\title{
Development of zero energy flexible unit with no Infrastructure for disaster and disaster response
}

\author{
Beungyong Park ${ }^{1, *}$, Jinkyun Cho ${ }^{1}$, Yongdae Jeong ${ }^{1}$, and Sangmoon Lee ${ }^{1}$ \\ ${ }^{1}$ Energy \& Environment Business Division, Korea Conformity Laboratories (KCL), Jincheon, 27872, South Korea
}

\begin{abstract}
In this paper a new kind of unit-prefabricated building is shown. The unit-prefabricated buildings are made up living unit, energy unit, water unit. The each unit was adapted new combine structure function as a high flexible design type. Moreover the design trend implemented the energy insulation, Solar PV panels, Energy storage system which are maintained for zero energy buildings. We made a prototype for zero energy flexible residential unit. The first step, we was evaluated physical performance and living environment, insulation, airtightness, thermal environmental, acoustic performance. The second step we was evaluated energy performance building to design heating and cooling system to combined PV, ESS system in the different plan type, and climate. As a results, The insulation performance wall was $0.18 \mathrm{~W} /\left(\mathrm{m}^{2} \cdot \mathrm{K}\right)$. The results of air-tightness was 12.13 ACH@50 (1/h). Further research we develop the structure and construction technology for zero energy flexible unit. To designed the high performance energy performance for zero energy building in the natural disaster.
\end{abstract}

\section{Background}

In recent years, the frequency of disaster occurrence has increased sharply around the world [1,2]. A disaster can damage people's lives, bodies, and properties as well as the nation, and is defined in terms of natural disaster and social disaster [3]. According to the worldwide statistics of disasters in 2017, the following natural disasters and damages occurred: cold waves and heavy snowstorms in Europe; a total of 81 incidents of tornadoes in the U.S. along with a big forest fire in California; and heavy snowfalls, typhoons, earthquakes, etc., in Japan $[1,2]$. In South Korea, the disasters such as cold wave, heat wave, tropical night, and typhoon are occurring frequently as well, and the safety of people is threatened as large losses of lives and properties have occurred due to forest fire, big fire on densely concentrated buildings, and collapse of building structures. For example, on November 15, 2017, apartment buildings were destroyed and many people lost their homes in Pohang area due to an earthquake. When a disaster occurs, it is required to provide food and temporary housing quickly to victims. Up until now, local public facilities such as schools, religious facilities, and public buildings were used as temporary shelters. On the other hand, when it is difficult to provide temporary housing, portable facilities like emergency tents and containers are used. As another type of temporary housing, there is industrialized housing. It can be mass-produced and because it is easy to transport and simple to assemble owing to light materials, it has an advantage that a building structure can be constructed relatively easily. Therefore, it can be utilized as a major solution for post-war urban recovery problem and housing problem. Consequentially, it is assessed as a good alternative of temporary housing. However, when infrastructures for electricity, water, and gas supply are not in place for the aforementioned temporary houses, portable facilities, and industrialized housings, it will be difficult to sustain a stable and comfortable life. Therefore, it is necessary to develop an infrastructureresponse type residence model whereby victims can reside and live temporarily when a disaster occurs, even if there is no infrastructure and no temporary house where victims can reside while feeling relieved.

This study aims to develop a flexible-unit type infrastructure-free residence for disaster response. To this end, first, the current domestic and overseas statuses of modular houses used for temporary houses in disaster situations are investigated. Second, by using a mock-up model of temporary house, a building performance is evaluated in the perspective of energy. Thermal insulation, air-tightness, and condensation, which are major technologies that can strengthen the building energy performance, are targeted. Third, for a situation with no infrastructure, the energy saving performance and energy-independence potentials are investigated through improvement of element technologies to develop an energy-independent house.

\section{Theoretical Discussion and Case Studies}

According to Ryan E.Smith [4], the industrialized housing has advanced following the construction needs 
and requirements. In the world colonization history of Great Britain in the 16th and 17th centuries, settlement in India, Middle East, Africa, Canada, and United States required rapid construction plans, and components (wood material kits) were manufactured in England and transported to all over the world by ships. The first record is the year 1624. Afterward, the on-site method, in which panels, i.e., components, are assembled on site, and the out-site method, in which components are assembled in factory and transported, are developed, and they are called modularization method. The modular structures can be classified into residential and commercial uses. In the case of residential use, it is further classified into temporary type and permanent type. In the case of modular commercial buildings, the temporary types include construction site trailer, mobile classroom, communication pod, and exhibition room. The permanent type is categorized into the dormitory, healthcare facility, hotel, government building, school, etc. The overseas modular building structure market has been formed mainly in the advanced countries like European countries, Japan, USA, Australia, and Canada, and in the case of U.K., which has the largest market size, the modular buildings have $2.1 \%$ market share of the total construction market. The market size is estimated to be from 1.34 trillion Korean won minimum to 4.2 trillion won maximum [5].

\subsection{Literature Review}

In South Korea, studies on disaster relief housing were mostly for architectural planning such as temporary housing facility's planned requirements, housing methodology, and needs. Kim et al.[6] presented types and plans of temporary housing relief to propose architectural countermeasures of disaster refugees. Time series types structures, and construction methods were classified and examined, and a relief housing suitable for open system modular housing was proposed. Moon et al.[7] mentioned that temporary housing is affected by climate, structure, material, and period, and the structure is the most important factor, and separated fixed and portable housings according to the structural characteristics. The relief housing development of Lim et al.[8] can be seen as a representative study on practical development. They developed a relief housing of modular standard elevation type. The pilot application was examined by using a temporary shelter of subway station. Wang et al. [9] proposed a horizontal expansion method based on joining for development of modular method-applied temporary housing. Through the design and mock-up module fabrication, they mentioned the need for additional technique developments with respect to reinforcing air-tightness when joining, horizontal leveling when joining units, and locking method of unit and unit. Like these, disaster relief housing plans and temporary modular housings are developed, but they are limited to technical developments of plans, structure aspect, and joining of modules. In fact, there are few studies on thermal insulation performance in the environmental performance aspect of house, and going further, an energy-independence performance of facility aspect applying new and renewable energy and energy storage systems.

\subsection{Domestic and Overseas Case Analysis of Modular Housing for Disaster Response}

Table 1 summarizes the research results for climates, shape, and vertical/horizontal expansion of modular disaster relief housing in South Korea and overseas. Typically, the shapes include module, container, combination of container and tent, assembly type, and box unit type. Each type is classified as either horizontal or vertical space expansion type due to structural difference according to the shape characteristics. In the case of when the stability of structure is not secured, horizontal expansion is common, and the modular and container types that have steel structure facilitate vertical expansion structures. According to the climate characteristics, the features such as finish and design of exterior material of envelope were different. Specifically, they are as follows. The type A of South Korea is a modular type and facilitates horizontal and vertical expansion whereby the units (living room unit, utility unit) can be configured according to the number of household members. It has a steel structure, and uses steel panels for the exterior material. The type A of USA is a bolting assembly type of container shape that facilitates vertical expansion. It was supplied to the Oklahoma hurricane refugees, and it has a rectangular floor plan of temporary container, in which housing, bathroom, and kitchen exist. The type B of USA has vertical expandability of container and tent types. The division of rooms and conversion of tent are easy and space expansion of kitchen, bathroom, and storage room can be easily and freely performed. It can accommodate up to two households based on a family of four people. The type C of USA is a modular type and a prefabricated system. Although it does not have a vertical or horizontal space expansion function, it is designed to withstand storms. The type D of USA is an assembly type and vertical and horizontal expansions are possible. It can be easily assembled and expanded without using a tool, and it can be installed even on an uneven terrain. Since aluminum insulation panels are used, it can be easily reused and easily expanded in various types such as temporary classrooms and offices as well as assembled houses. The type A of Japan is a container type and facilitates horizontal expansion. After being used for temporary houses of the earthquake and tsunami refugees, they can be transformed into permanent structures. By connecting two containers, the space can be expanded. The type B of Japan is a container type and facilitates vertical and horizontal expansions. Even on a sloped or narrow land, if the basic container area is secured, the house can be installed to a maximum of three stories. Since a frame of container is used, it has excellent internal performance and can be used permanently. Moreover, because space expansion is easy, it has a structure that can adapt to various area sizes according to the number of accommodated people. 
Table 1 Summarizes the research results for modular disaster relief housing

\begin{tabular}{|c|c|c|c|c|}
\hline No & Nom & Types & Extand Function & \\
\hline & Natics & Climate & Area & mages \\
\hline Korea-A & Temporary relief housing & Modular & $\begin{array}{l}\text { Horizon }(\bigcirc) \\
\text { Vertical }(\bigcirc)\end{array}$ & \\
\hline & & Temperate rainy & $\begin{array}{l}9 \mathrm{~m}^{2}, 18 \mathrm{~m}^{2}, \\
27 \mathrm{~m}^{2}, 36 \mathrm{~m}^{2}\end{array}$ & \\
\hline USA - A & MODS international shipping & Container & $\begin{array}{l}\text { Horizon }(\times) \\
\text { Vertical }(\bigcirc)\end{array}$ & \\
\hline & & Monsoon & $29.7 \mathrm{~m}^{2}$ & \\
\hline USA - B & Transportable emergency & $\begin{array}{c}\text { Container } \\
\text { / Tent }\end{array}$ & $\begin{array}{l}\text { Horizon }(\bigcirc) \\
\text { Vertical }(\times)\end{array}$ & \\
\hline & & Mediterranean & - & \\
\hline USA - C & House arc & Prefab & $\begin{array}{l}\text { Horizon }(\times) \\
\text { Vertical }(\times)\end{array}$ & \\
\hline & & Subtropical & $13.9 \mathrm{~m}^{2}$ & \\
\hline USA - D & Rapidly deployable emergency & Prefab & $\begin{array}{l}\text { Horizon }(\bigcirc) \\
\text { Vertical }(\bigcirc)\end{array}$ & \\
\hline & modular living unit & Subtropical & - & \\
\hline JAPAN - & EX-container project & Container & $\begin{array}{l}\text { Horizon }(\bigcirc) \\
\text { Vertical }(\times) \\
\end{array}$ & \\
\hline A & & Temperate rainy & $24 \mathrm{~m}^{2}$ & \\
\hline JAPAN - & Multi-storey temporary housing & Container & $\begin{array}{l}\text { Horizon }(\bigcirc) \\
\text { Vertical }(\bigcirc) \\
\end{array}$ & \\
\hline B & by shigeru Ban & Temperate rainy & $\begin{array}{l}12.3 \mathrm{~m}^{2}, 14.1 \mathrm{~m}^{2}, \\
29.4 \mathrm{~m}^{2}, 42.6 \mathrm{~m}^{2}\end{array}$ & \\
\hline $\mathrm{EU}-\mathrm{A}$ & Ikea develops flat-pack refugee & Prefab & $\begin{array}{l}\text { Horizon }(\times) \\
\text { Vertical }(\times) \\
\end{array}$ & \\
\hline (Sweaden) & shelters & Ocean climate & - & \\
\hline EU - B & DH1 flat-pack disaster house & Prefab & $\begin{array}{l}\text { Horizon }(\times) \\
\text { Vertical }(\times)\end{array}$ & \\
\hline (England) & & West coast oceanic & - & \\
\hline $\begin{array}{l}\text { EU - C } \\
\text { (Italy) }\end{array}$ & Gabriele aramu: sliding hub & $\begin{array}{l}\text { Box unit } \\
\text { Mediterranean }\end{array}$ & $\begin{array}{c}\text { Horizon }(\bigcirc) \\
\text { Vertical }(\times) \\
-\end{array}$ & \\
\hline
\end{tabular}

The type A of Europe has an assembly type structure and facilitates horizontal expansion. Since each material is panelized, installation is easy and space expansion is simple. It has a characteristic that maintains the indoor temperature easily by reflecting the solar heat according to the characteristic of oceanic climate region. The type $\mathrm{B}$ of Europe is an assembly type and facilitates horizontal expansion. Plywood panels of wood materials can be installed without nails or adhesives. This type can be used for houses of small units or shelter. The type $\mathrm{C}$ of Europe is a box unit type and facilitates horizontal expansion. Because transportation, installation, connection between units, and single isolation of unit are easy, it has an advantage in terms of space expansion.

\section{Characteristics of Developed Modular Housing}

Fig. 1 shows the conceptual diagram of flexible-unit type infrastructure-free (temporary) housing for disaster response. Each modular unit has a characteristic of having unit structure of $3 \mathrm{~m} \times 3 \mathrm{~m}$ size. It consists of a total of four function units: housing unit, energy (power supply) unit, water unit (greywater/sewage), and core 
unit (stairs/corridor). Because modular units are manufactured, they are convenient to move and transport, and owing to their cubical shape, vertical and horizontal space expandability is excellent. According to the use period, they can be used as either temporary facility or permanent facility. One combination of respective units become one house, and depending on the requirement of energy-isolated area and disaster area, they can be moved and installed independently. Moreover, there is a characteristic that units can be combined and expanded according to the functional requirements. To facilitate energy production and storage in a situation of no infrastructure, photovoltaic (PV) system and energy storage system (ESS) is included in the energy unit.

The water unit adopts a package water treatment system to implement the water storage of conventional water supply and recycling of rainwater and greywater to use them for residential water. The air-conditioning, heating, and hot water systems used for maintenance of living environment consist of system that produces energy by consuming electricity. The core unit is used for the purpose of horizontal and vertical movements of users and managers between housing unit, energy unit, and water unit. It is an assembly unit that facilitates expandability and extendibility of modular house

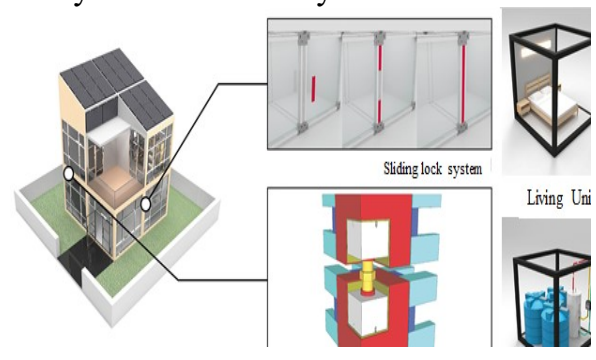

Fig. 1. Concept of flexible-unit infra free module housing

\section{Environmental performance test evaluation of mock-up modular house}

\subsection{Described mock-up module house}

The target modular house is a two-story single-family house above ground, and has $8.12 \mathrm{~m}^{2}$ building area, $16.25 \mathrm{~m}^{2}$ total floor area, and $5.99 \mathrm{~m}$ elevation. Fig. 2 shows the production process of modular house and Fig. 3 shows the composition of target walls. From the outer side, it consists of composite panel, thermal insulator, moisture-permeable waterproof sheet, plywood, glasswool, and gypsum board, in that order. After assembling the foundation and columns, the wall panels were assembled, followed by installation of windows and doors and finish of interior and exterior materials.

\subsection{Evaluation methods}

The present paper evaluates the architectural performance for the flexible-unit type modular house ("modular house" hereafter) of current level. As for the performance required in such a house, "Appendix 6: the performance and production standard of industrialized house" is defined in the "article 13 (performance and production standard of industrialized house) of regulation for house construction standard" of the Ministry of Land, Infrastructure and Transport Act number 362 [10]. Among them, the air-tightness performance and thermal insulation performance, which affect energy consumption, are evaluated in this section. Table 1 shows the industrialized house's air-tightness and thermal insulation evaluation standards and condensation prevention requirements. In the case of airtightness, the evaluation is performed by using " $\mathrm{KS} \mathrm{L}$ ISO 9972: thermal insulation and building airtightness measurement - fan pressurization method"[11] and the airtightness of 1.5 times/h must be maintained based on the pressure differential of $50 \mathrm{~Pa}$. In the case of thermal insulation, the evaluation is performed according to the "KS F 2278: thermal insulation test method of windows and doors"[12] and it must conform to the heat loss prevention standard of local region. In the case of condensation prevention performance, measurements are taken through a condensation prevention performance simulation of building structure by using a program suitable for international standards such as condensation prevention performance test method of ISO 10211 [13]. However, the temperature difference ratio (TDR) of surface temperature of joints and indoor/outdoor temperature must be 0.20 or less[14].
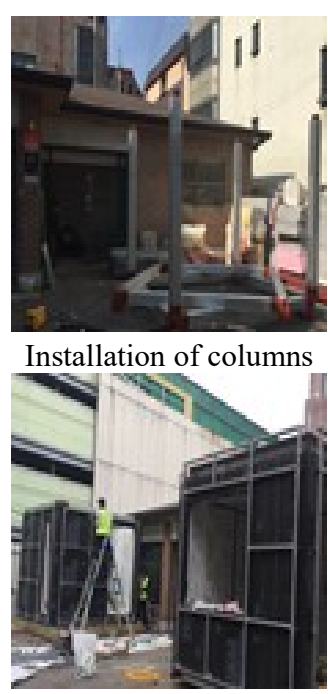

$1 \mathrm{~F} / 2 \mathrm{~F}$ Combination

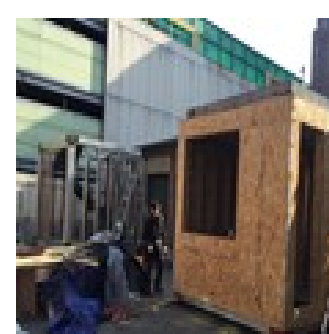

Installation of Walls

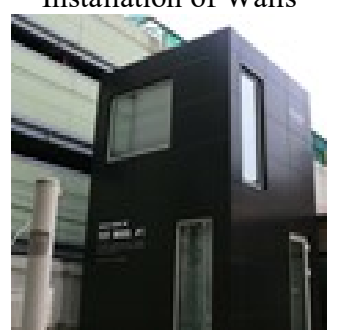

Finished
Fig. 2. Manufacturing process of module house

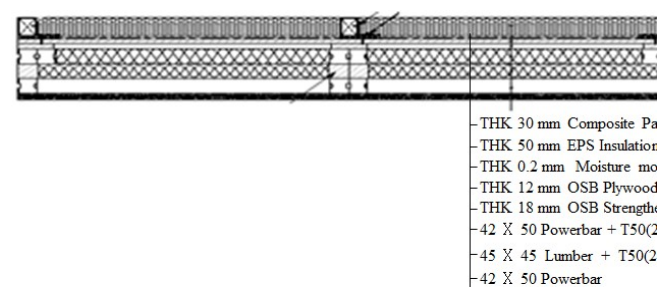

Fig. 3. Construction of walls

Fig. 4 shows the installation of the airtightness measurement device. A Minneapolis Blower Door 
Table 2. Performance standard of industrialized housing

\begin{tabular}{|c|c|c|}
\hline Item & Standard & Requirement \\
\hline Air Tightness & $\begin{array}{c}\text { KS L ISO } \\
9972\end{array}$ & $\begin{array}{c}\text { Airtightness } 1.5 \text { times } / \mathrm{h} \text {, at 50 Pa } \\
\text { pressure difference }\end{array}$ \\
\hline Insulation & KS F 2278 & $\begin{array}{c}\text { Suitable for heat loss prevention } \\
\text { standard }\end{array}$ \\
\hline Condensation & ISO 10211 & $\begin{array}{c}\text { Temperature difference ratio less } \\
\text { than } 0.20\end{array}$ \\
\hline
\end{tabular}

$\operatorname{TDR}=\left(T_{i}-T_{m}\right) /\left(T_{i}-T_{o}\right)$

device was connected to a door and it was made sure that there is no leakage at the joint of device and building. The parts that affect the airtightness, such as kitchen hood and power outlets were treated to be airtight. The outdoor temperature, wind speed, and indoor temperature were measured, which affect the measurement of airtightness. For the thermal insulation performance evaluation of modular house in this study, the specimen of external wall was composed in $2 \times 2 \mathrm{~m}$ size. Fig. 5 shows the installation of wall and thermal transmittance measurement device, which were composed according to KS F 2278. Furthermore, for the thermal bridge diagnosis of wall connection part of modular house, an indoor radiant heating device was installed to maintain $10^{\circ} \mathrm{C}$ or higher for the temperature difference between outdoor and indoor.

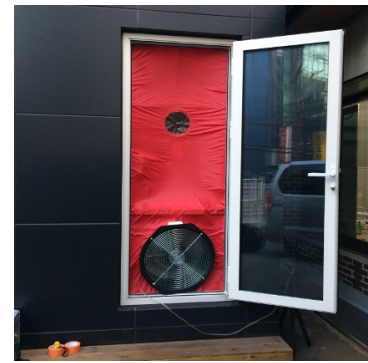

Fig. 4. Specification of measurement results

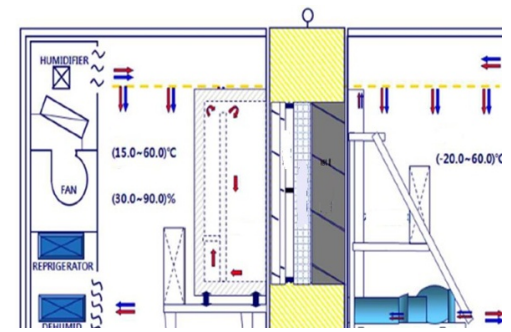

Fig. 5. Schematic of U-value test devices

\subsection{Results of environment performance}

Table 3 shows the air leakage rate and airtightness performance measurement results according to pressure difference. When the pressure difference of $50 \mathrm{~Pa}$ is applied, the air leakage rate is $(426 \pm 6) \mathrm{m} 3 / \mathrm{h}$ and the airtightness performance of $\mathrm{ACH} @ 50$ is $12.131 / \mathrm{h}$. This result demonstrates that the airtightness performance of ACH@50, which is proposed in the performance and production standards of industrialized house, does not satisfy $1.51 / \mathrm{h}$. Fig. 6 shows the relationship of air leakage rate with differential pressure. In the modular house, which is the target of the present evaluation,
Table 3. Results of air-tightness

\begin{tabular}{|c|c|c|c|}
\hline Items & Times & $\begin{array}{c}\text { Pressure } \\
\text { Difference }\end{array}$ & Results \\
\hline \multirow{5}{*}{$\begin{array}{l}\text { Measure } \\
\text { results }\end{array}$} & 1 & $29.2 \mathrm{~Pa}$ & $329 \mathrm{~m}^{3} / \mathrm{h}$ \\
\hline & 2 & $24.6 \mathrm{~Pa}$ & $304 \mathrm{~m}^{3} / \mathrm{h}$ \\
\hline & 3 & $20.1 \mathrm{~Pa}$ & $274 \mathrm{~m}^{3} / \mathrm{h}$ \\
\hline & 4 & $15.1 \mathrm{~Pa}$ & $240 \mathrm{~m}^{3} / \mathrm{h}$ \\
\hline & 5 & $10.0 \mathrm{~Pa}$ & $197 \mathrm{~m}^{3} / \mathrm{h}$ \\
\hline Test & \multicolumn{2}{|c|}{ Leakage $50 \mathrm{~Pa}$} & $(426 \pm 6) \mathrm{m}^{3} / \mathrm{h}$ \\
\hline Results & \multicolumn{2}{|c|}{ ACH@50 } & $12.131 / \mathrm{h}$ \\
\hline
\end{tabular}

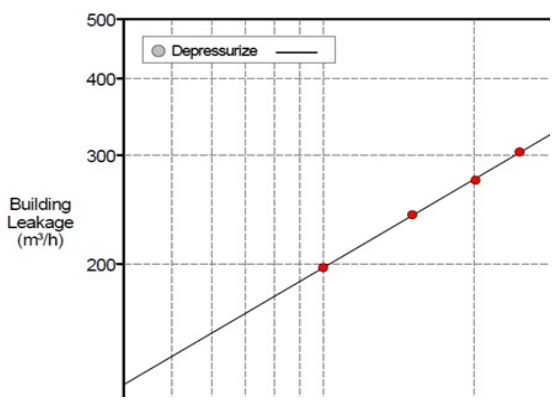

Fig. 6. Specification of measurement results

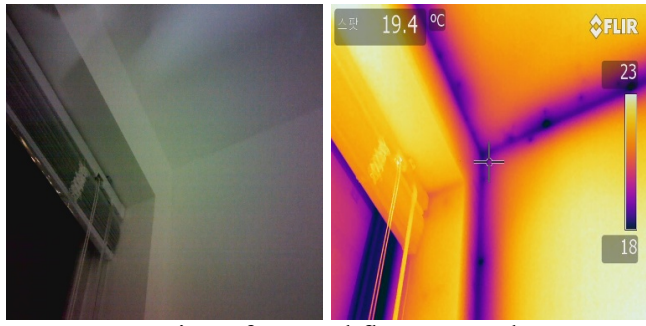

Location of Second floors top edge

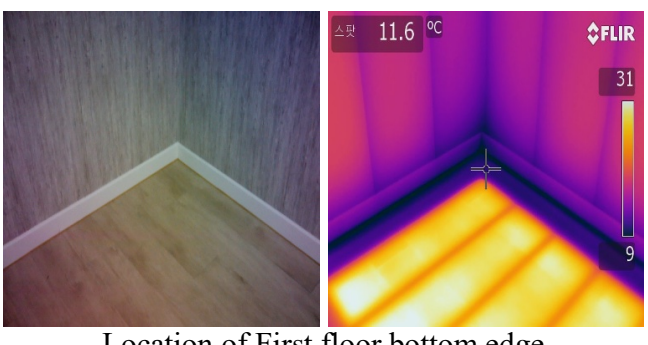

Location of First floor bottom edge

Fig. 7. Diagnosis results of thermal bridge

structural components are dry type and It will be difficult to ensure the airtightness performance if airtight construction is not performed for the joints. The thermal transmittance of wall according to KS F 2278 is .measured as $0.180 \mathrm{~W} /\left(\mathrm{m}^{2} . \mathrm{K}\right)$. The window performance shows that when the separate test report (RK2014-0103) value is referenced, the thermal transmittance is $0.996 \mathrm{~W} /\left(\mathrm{m}^{2} . \mathrm{K}\right)$. This satisfies the given standard when compared with the standard for exterior wall of living room $\left(0.240 \mathrm{~W} /\left(\mathrm{m}^{2} . \mathrm{K}\right)\right.$ or less $)$ and window and door $\left(1.500 \mathrm{~W} /\left(\mathrm{m}^{2} . \mathrm{K}\right)\right.$ or less $)$ of nonapartment houses in Central Region II of South Korea stated in the Energy Saving Standard of Buildings (the notification no. 2017-881 of Ministry of Land, Infrastructure and Transport). The diagnosis of thermal bridge part using thermal image camera was performed at the outdoor temperature of $(7.8 \pm 0.3){ }^{\circ} \mathrm{C}$, indoor 
temperature of $(26.3 \pm 1.8){ }^{\circ} \mathrm{C}$, and indoor and outdoor temperature difference of $(18.5 \pm 1.5){ }^{\circ} \mathrm{C}$, which was a condition that a thermal bridge can occur. Fig. 7 shows the diagnosis result of thermal bridge part of modular house. It was confirmed that thermal bridge occurred at the joint between wall modules and at the edges. For the occurrence evaluation of condensation, a program evaluation is provided in ISO 10211, but in this section, the calculation was performed with the measured values by using the TDR equation. The required value of condensation evaluation standard of the industrialized house is TDR 0.02 or less. The TDR of joint of ceiling part is 0.37 and the TDR of joint of floor part is 0.79 , and it was determined that the performance should be secured to prevent the condensation. The above results of condensation examination are the TDR calculation results using the measurement values at the condition of indoor and outdoor temperature difference $(18.5 \pm 1.5)$ $\mathrm{a}^{\circ} \mathrm{C}$, and additional study is under progress according to the ISO 10211's method and analysis criteria. Overall, tightness performance should be secured through joining construction between wall components, and a thermal bridge (condensation) prevention method is required. Especially, in the case of airtightness, airtightness design, proper construction and installation, and technical application of airtightness gasket are examined to improve the airtightness at the parts where the followings meet or exist in the window frames, window and window frame, and door and door frame.

\section{Conclusion}

The present study researched the current domestic and overseas status with the purpose of developing a flexible-unit type infrastructure-free housing for disaster response. Furthermore, for the current level mock-up modular house, the diagnosis was performed with respect to the airtightness, thermal insulation, and thermal bridge part, which are classified as building environmental performance factors of industrial house by the Ministry of Land, Infrastructure and Transport. Based on the research result, the energy independence feasibility was investigated according to the reduction of heating/cooling energy requirement based on the airtightness improvement of improved model design and the adoption of new renewable energy. The study results are summarized as follows.

(1) The airtightness performance ACH@50 of mock-up modular house was $12.131 / \mathrm{h}$ and the thermal transmittance of wall was $0.180 \mathrm{~W} /\left(\mathrm{m}^{2} . \mathrm{K}\right)$, which did not satisfy the airtightness performance suggested by the performance and production standards of industrialized house. However, the thermal insulation performance (Central Region II) satisfied the standard. To respond to a disaster situation according to the period, the technology needs to be improved to satisfy the airtightness performance of industrialized house.
This research was supported by grant of the research fund of the Korea KAIA(Korea Agency for Infrastructure Technology Advancement) in 2018. Project numbwe: 18TBIP-C144010-01.

\section{References}

1. Ministry of the Interior and Safety, Disaster Year Book 2017, (2018)

2. Ministry of the Interior and Safety, Statistical Yearbook of Natural Disaster 2017, (2018)

3. Misfortune and the safety supervision law, Low No. 15764, Ministry of the interior safety (2018)

4. Ryan E. S., Prefab Architecture a Guide to Modular Design and Construction, pp 5. (2010)

5. Jo, B-H., Lee, W. I., Global Research - Overcome Market of Modular Architecture(England), Korea Institute of Construction Engineering and Management, Vol. 15, No. 4, (2014)

6. Kim, K.H., A Study on the Architectural Responses on the Post-disaster Refugees Housing - Especially on the Open System Modular Housing, Decree of the Inha-university, (2005)

7. Moon, J. I., A Study on the Planning Method of Temporary Dwellings for Sufferers from a Disaster, Decree of the Yonsei University, (2007)

8. Infrastructure and Transport R\&D Report, Development of a Temporary Living Space Systems Against Disasters, The Ministry of Land, (2014)

9. Wang, W. C., Lim, S. H., A Study on the Space Expansion of Temporary Housing to Utilize Modular mock-up, Journal of the Architectural Institute of Korea Planning \& Design, Vol. 30, No. 4, pp. 103111, (2014)

10. Standard of Construction Housing Low No. 362, Ministry of the Interior and Safety (2016)

11. Korea Agency for Technology and Standards, KS L ISO 9972 Thermal Insulation - Determination of Building Airtightness - Fan Pressurization Method, (2016)

12. Korea Agency for Technology and Standards, KS F2278 Standard Test Method for Thermal Resistance for Windows and Doors, (2017)

13. International Standards, ISO 10211 Thermal Bridges in Building Construction - Heat Flows and Surface Temperatures - Detailed Calculations, (2007)

14. Korean Institute of Architectural Sustainable Environment and Building Systems, Building Airtightness Criteria, Appendix 2 pp 8 (2013)

\begin{tabular}{|ll|}
\hline \multicolumn{2}{|c|}{ Nomencalture } \\
$T$ & temperature $\left({ }^{\circ} \mathrm{C}\right)$ \\
Subscripts and superscripts \\
$i$ & indoor air \\
$m$ & indoor minimum surface temperature \\
$o$ & outdoor air \\
\hline
\end{tabular}

